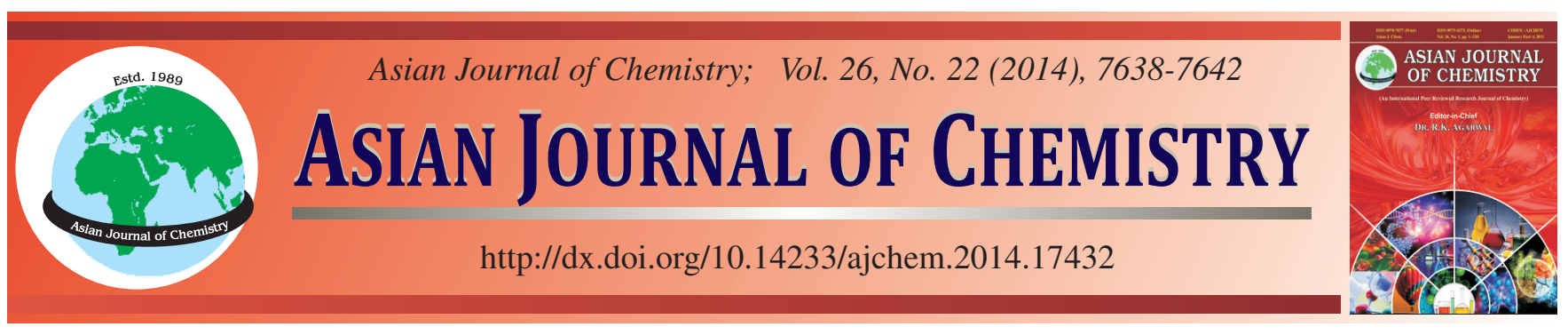

\title{
Estimation of Germanicol by Validated HPTLC Densitometric Method in Leaves of Different Species of Genus Ficus
}

\author{
N.A. Siddiqui ${ }^{1}$, O.A. Basudan ${ }^{1}$, M.F. Alajmi ${ }^{1}$, A.J. Al-Rehaily ${ }^{1}$, S.I. Alqasoumi ${ }^{1}$, \\ M.S. ABDEl-KADER ${ }^{2}$, P. AlAm², A.R.M. DONIA ${ }^{2}$ and P. Alam ${ }^{1, *}$
}

\begin{abstract}
${ }^{1}$ Deptartment of Pharmacognosy, College of Pharmacy, King Saud University, Riyadh, Kingdom of Saudi Arabia
${ }^{2}$ Department of Pharmacognosy, College of Pharmacy, Salman Bin Abdulaziz University, Al-Kharj, Kingdom of Saudi Arabia

*Corresponding author: Tel: +96 6 551362901; E-mail: alamperwez007@gmail.com
\end{abstract}

A simple and sensitive HPTLC method was developed for estimation of germanicol in the leaves of five different species of genus Ficus (Ficus carica, Ficus nitida, Ficus ingens, Ficus palmata and Ficus vasta) grown in Kingdom of Saudi Arabia. The chromatography was performed on glass-backed silica gel $60 \mathrm{~F}_{254}$ HPTLC plates with solvents hexane: chloroform $(55: 45$, v/v) as mobile phase. After the development of HPTLC plate it was derivatized with $p$-anisaldehyde reagent to give well resolved and compact spot of germanicol. The developed method was found to give a compact spot for germanicol $\left(R_{\mathrm{f}}=0.39 \pm 0.01\right)$ at $525 \mathrm{~nm}$. Germanicol was found to be present in four species i.e., F. carica $(0.21 \%$, w/w), F. nitida $(0.22 \%$, w/w), F. palmata $(1.06 \%$, w/w) and $F$. vasta $(0.27 \%$, w/w) while it was absent in the $F$. final. The proposed method can be used in study of degradation kinetics of germenicol and its determination in plasma.

Keywords: Ficus species, Leaves, Germanicol, HPTLC, Validation.

\section{INTRODUCTION}

The genus Ficus includes about 800 species $^{1}$ of woody trees, shrubs and vines and their fruits generally known as figs, distributed widely in tropical and subtropical regions ${ }^{2}$. The common fig (Ficus carica) originated in the Old World Tropics-Asia Minor and the Mediterranean region. Figs are oblong or pear-shaped syconium fruit of a cultivated tree of the mulberry (Moraceae) family. Figs have been used as a sweetener for thousands of years and are good from nutrition point of view and health benefits ${ }^{3}$. Though figs are seasonal fruits but they are available throughout the year in dried form. Fresh figs, contain poly-phenolic flavonoids whose antioxidant property is comparable to that of apples at $3200 \mu \mathrm{mol} /$ $100 \mathrm{~g}$. From ancient time figs were used as food and traditional medicine, contains laxative substances, flavonoids, sugars, vitamins $\mathrm{A}$ and $\mathrm{C}$, acids and enzymes ${ }^{4}$. Some other important phytoconstituents reported in the genus Ficus are coumarins ${ }^{5}$, furocoumarin glycosides ${ }^{6}$, isoflavones ${ }^{7}$, lignans ${ }^{8}$, sterols and/ or terpenes ${ }^{9}$ and chromone ${ }^{10}$. Ficus species have been used in folk medicine as anticancer and antiinflammatory ${ }^{11}$, antiepileptic $^{12}$, antioxidant ${ }^{13}$, antihepatotoxic ${ }^{14}$, gastroprotective ${ }^{15}$, antidiabetic ${ }^{16}$ and as antimalarial ${ }^{17}$. Dried figs are concentrated sources of energy (100 g dried figs provide 249 calories $)^{18}$.
Germanicol is a pentacyclic triterpene occurs in numerous plants $^{19-21}$. It was reported to posses antibacterial ${ }^{22}$, antifungal ${ }^{23}$ and anti-inflammatory ${ }^{24}$ activities. Extensive literature survey revealed that not much analytical methods have been tried for the identification as well as quantification of germanicol in plant extracts and in formulations. Only one method reported for its identification by GC/MS ${ }^{25}$. Also a validated HPTLC method is not yet reported for the quantification of germanicol in different species of genus Ficus grown in Kingdom of Saudi Arabia. Therefore, the aim of present study was to develop and validate a sensitive and cost effective HPTLC densitometric method for the quantitation of germanicol in methanol extracts of leaves of five above mentioned of species Ficus grown in Kingdom of Saudi Arabia. The proposed method was validated as per ICH guideline, $1996^{26}$.

\section{EXPERIMENTAL}

The leaves of five species of genus Ficus i.e. F. carica (Sample 1), F. nitida (Sample 2), F. ingens (Sample 3), F. palmata (Sample 4) and Ficus vasta (Sample 5) were collected from Southern region of Kingdom of Saudi Arabia and authentified by Dr. Mohammed Yusuf, Field taxonomist, Medicinal Plant Collection and Survey Unit, Department of Pharmacognosy, College of Pharmacy, King Saud University, Kingdom of Saudi 
Arabia. Specimens of the plants were deposited in the Department of Pharmacognosy, College of Pharmacy, King Saud University, Kingdom of Saudi Arabia.

Germanicol (standard) was obtained from Sigma Aldrich. Analytical grade reagents and solvents (toluene, methanol) were purchased from Winlab and BDH (U.K.). Glass-backed Silica gel $60 \mathrm{~F}_{254}$ HPTLC plates $(20 \times 10 \mathrm{~cm})$ were purchased from Merck (Darmstadt, Germany). Methanol solution of standard and different extracts were applied to chromatographic plates bandwise, by means of a CAMAG automatic TLC sampler-4 (CAMAG, Muttenz, Switzerland) and developed in ADC2 (automatic development chamber) (CAMAG, Muttenz, Switzerland). TLC Plates were then documented by CAMAG TLC Reprostar 3 and scanned by CATS 4 (CAMAG).

Preparation of standard stock solution: Stock solution of standard (germanicol) $\left(1 \mathrm{mg} \mathrm{mL}^{-1}\right)$ was prepared in choloroform. $1 \mathrm{~mL}$ of the stock solution was diluted in $10 \mathrm{~mL}$ choloroform to make the concentration $100 \mathrm{ng} / \mu \mathrm{L}$. For calibration, 1-8 $\mu \mathrm{L}$ standard solution was applied to a HPTLC plate to furnish concentration in the range 100-800 ng per band, respectively.

Preparation of samples: The leaves of sample 1, sample 2, sample 3, sample 4 and sample 5 were air-dried and pulverized. $500 \mathrm{~g}$ of the powdered material were packed in muslin cloth and subjected to soxhlet extractor for continuous hot extraction with methanol for $72 \mathrm{~h}$. Thereafter methanol extracts were filtered through Whatman paper no. 42 and the obtained extract was concentrated under reduced pressure and finally vacuum dried. The yield was $4,5.1,5.6,4.9$ and $6.5 \%$ w/w, respectively.

TLC instrumentation: Chromatographic analysis was done on $(20 \mathrm{~cm} \times 10 \mathrm{~cm})$ HPTLC plates. Samples were applied as bands $6 \mathrm{~mm}$ wide and $7.7 \mathrm{~mm}$ apart by Linomat IV sample applicator. The application rate of sample on plate was 160 $\mathrm{nL} \mathrm{S}{ }^{-1}$. The plates were developed in previously saturated 20 $\times 10 \mathrm{~cm}$ twin-trough glass chamber [at room temperature $(25$ $\left.\pm 2{ }^{\circ} \mathrm{C}\right)$ and relative humidity $\left.(60 \pm 5 \%)\right]$. The plates were dried at room temperature and then derivatized with $p$ anisaldehyde reagent and heated to identify compact bands.

Preparation of calibration graphs: Calibration graph for standard (germanicol) was prepared by applying a series of spots of germanicol with eight different volumes so as to get different amount of germanicol per spot. They were prepared with respect to area $v s$. amount per spot.

Method development: Chromatogram was developed for germanicol by selecting the mobile phase after trying several combinations of solvents. The best resolution was observed in the selected [hexane: chloroform $(55: 45, \mathrm{v} / \mathrm{v})$ ] mobile phase. The same mobile phase has been employed for the separation of methanol extracts of samples 1,2,3,4 and 5. The optimized saturation time was observed as $20 \mathrm{~min}$. The densitometric analysis was performed at absorption maxima of wave length $525 \mathrm{~nm}$ in absorbance/reflectance mode with CATS 4 operated by WinCATS software (Version 1.2.0).

Method validation: Method validation was carried out as per international conference on harmonization ( $\mathrm{ICH}$ ) guidelines for linearity range, precision, accuracy, robustness, LOD, LOQ and recovery.
Precision (inter and intraday) and accuracy of the assay were evaluated by performing replicate analyses $(n=6)$ of samples at three quality control (QC) levels i.e., low, medium and high of 150, 300 and $600 \mathrm{ng}^{\text {band }}{ }^{-1}$, respectively. Interday precision and accuracy were determined by repeating the intra-day assay on three different days. Precision was expressed as per cent coefficient of variation $(\% \mathrm{CV})$ of measured concentrations for each calibration level whereas accuracy was expressed as percentage recovery.

Robustness was studied in triplicate at $300 \mathrm{ng}$ band $^{-1}$ by making small changes to mobile phase composition, mobile phase volume and duration of mobile phase saturation and activation of TLC plates. The results were examined in terms of per cent relative standard deviation (\% RSD) and standard error (SE) of peak areas. Mobile phases prepared from hexane: chloroform in different proportions $(55: 45, \mathrm{v} / \mathrm{v} ; 50: 40, \mathrm{v} / \mathrm{v}$; $53: 47, \mathrm{v} / \mathrm{v} ; 58: 42, \mathrm{v} / \mathrm{v}$ ) were used for chromatography. Mobile phase volume and duration of saturation investigated were 20 $\pm 2 \mathrm{~mL}(18,20$ and $22 \mathrm{~mL})$ and $20 \pm 10 \mathrm{~min}(10,20$ and 30 min), respectively. The plates were activated at $110{ }^{\circ} \mathrm{C}$ for 30 min before chromatography.

The LOD and the LOQ were calculated based on the standard deviation (SD) of the response and the slope (S) of the calibration curve at levels approaching the LOD according to the formulae: $[\mathrm{LOD}=3.3(\mathrm{SD} / \mathrm{S})$ and $\mathrm{LOQ}=10(\mathrm{SD} / \mathrm{S})]$. The standard deviation of the response was determined based on the standard deviation of $y$-intercepts of regression lines.

Recovery was studied by applying the method to drug samples to which known amounts of marker corresponding to 50,100 and $150 \%$ of the germanicol had been added. Each level was analyzed in triplicates. This was to check the recovery of germanicol at different levels in the extracts.

\section{RESULTS AND DISCUSSION}

The developed method was found to be effective in separation of constituents present in the samples (1,2, 3, 4 and 5) and exhibiting sharp peaks of standard (germanicol) as well, with the selected mobile phase under chamber saturation conditions at a wavelength of $525 \mathrm{~nm}$ in absorbance/reflectance mode (Fig. 1). Compact, symmetrical and high resolution bands of germanicol were obtained at $R_{f} 0.39 \pm 0.001$ (Fig. 2).

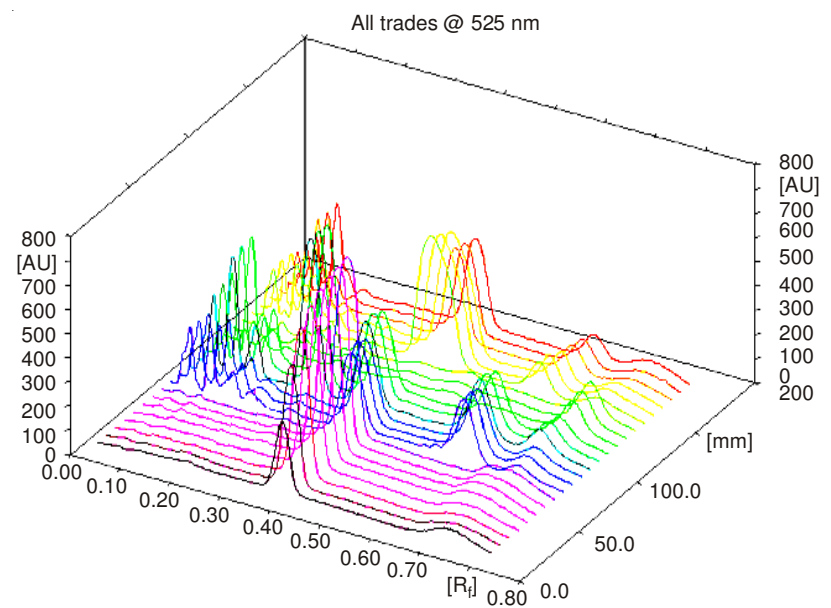

Fig. 1. 3D-display of all tracks at $525 \mathrm{~nm}$; mobile phase: hexane: chloroform $(55: 45, \mathrm{v} / \mathrm{v})$ 


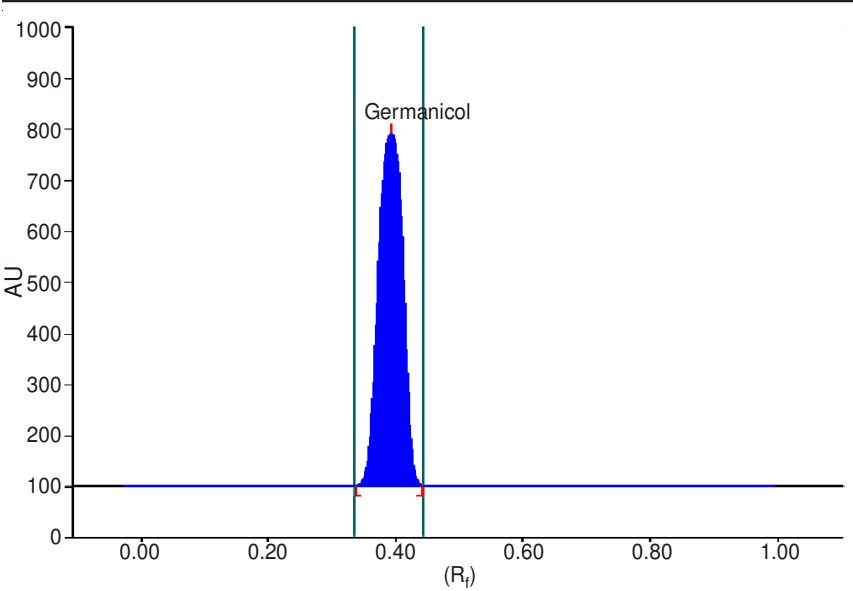

Fig. 2. Chromatogram of standard germanicol (800 ng $\left.\operatorname{spot}^{-1}, R_{f}=0.39\right)$, peak 1; mobile phase: hexane: chloroform $(55: 45, \mathrm{v} / \mathrm{v})$

The developed method was found to be quite selective with good baseline resolution. The identity of the bands of compounds in the sample extracts were confirmed by overlaying their absorption spectra with those of the standards (Fig. 3).

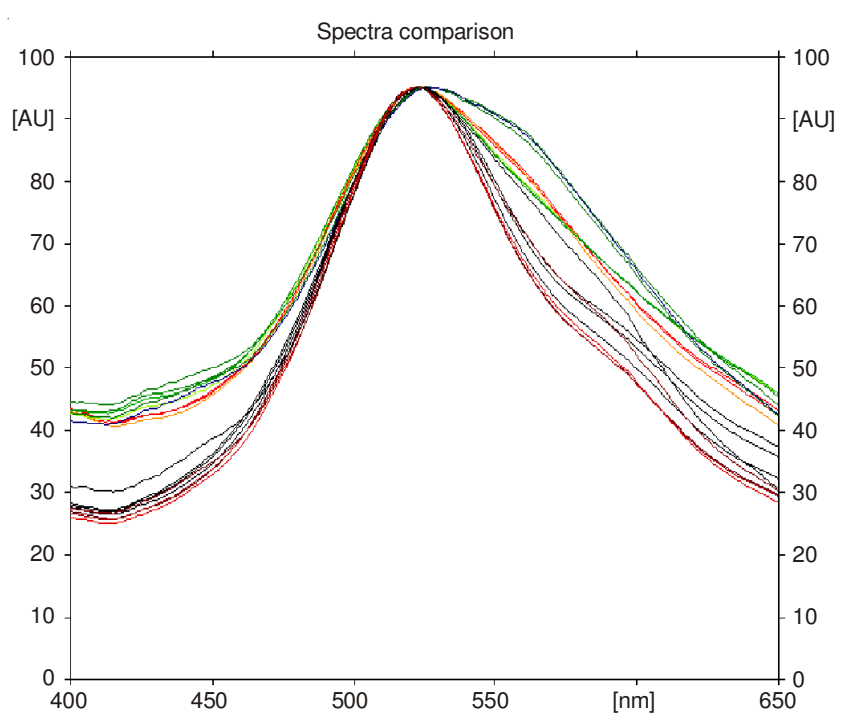

Fig. 3. Spectral comparison at $525 \mathrm{~nm}$; mobile phase: hexane: chloroform $(55: 45, \mathrm{v} / \mathrm{v})$

Method validation: Linearity of germanicol was validated by the linear regression equation and correlation coefficient. The eight-point calibration curve for germanicol was found to be linear in the range of 100-800 ng. Regression equation and $\mathrm{r}^{2}$ for the reference compound were observed as $\mathrm{Y}=$ $2.895 \mathrm{X}+29.694$ and 0.998 , respectively which revealed a good linearity response for developed method (Table-1). The mean value with \pm SD of the slope was $2.895 \pm 0.004$ and intercept was $29.694 \pm 0.003$ for germanicol. No significant difference was observed in the slopes of standard plots $(\mathrm{P}>$ $0.05)$. Table- 2 presents intra-day and inter-day precision and accuracy for the assay of germanicol at three quality control (QC) levels $\left(150,300\right.$ and $\left.600 \mathrm{ng}^{\text {band }}{ }^{-1}\right)$. Intra-day and interday precisions $(n=6)$ for germanicol were found to be 1.46 1.63 and 1.61-1.84 \%, respectively, which demonstrated the good precision of proposed method. However, intra-day and interday accuracy of germanicol were observed as 99.3-99.9 and 99.2-99.6\%, respectively. These results indicated the accuracy of the proposed method. The standard deviation (SD) and per cent relative standard deviation (\% RSD) were also calculated at $300 \mathrm{ng}$ band $^{-1}$ concentration level of germanicol. The low value of SD and \% RSD obtained after introducing small deliberate changes in the method indicate that the method was robust (Table-3). LOD and LOQ were found to be 33 and $99 \mathrm{ng}$ band $^{-1}$, respectively (Table-1). This indicated that the proposed method exhibits a good sensitivity for the quantification of above compound. Good recoveries were obtained by the fortification of the sample at three quality control levels of germanicol. It is evident from the results that the per cent recoveries for germanicol after sample processing and applying were in the range of 99.3-99.8 \% as shown in Table-4.

HPTLC analysis of prepared samples: The utility of the proposed method was evaluated by applying this method for the quantification of germanicol in the samples 1, 2, 3, 4 and 5. Out of these five samples evaluated for the quantification of germanicol, four samples i.e., sample 1 (F. carica), sample

TABLE-1

$\mathrm{R}_{f}$, LINEAR REGRESSION DATA FOR THE CALIBRATION CURVE AND SENSITIVITY PARAMETER FOR GERMANICOL

\begin{tabular}{ll}
\hline \multicolumn{1}{c}{ Parameter } & \multicolumn{1}{c}{ Germanicol } \\
\hline $\mathrm{R}_{\mathrm{f}}$ & $0.39 \pm 0.01$ \\
Linearity range $\left(\right.$ ng band $\left.^{-1}\right)$ & $100-800$ \\
Regression equation & $\mathrm{Y}=2.895 \mathrm{X}+29.694$ \\
Correlation coefficient & $\left(\mathrm{r}^{2}\right) 0.998$ \\
Slope \pm sd & $2.895 \pm 0.004$ \\
Intercept \pm sd & $29.694 \pm 0.003$ \\
Standard error of slope & 0.004 \\
Standard error of intercept & 0.003 \\
LOD & $33 \mathrm{ng} \mathrm{band}^{-1}$ \\
LOQ & $99 \mathrm{ng} \mathrm{band}^{-1}$ \\
\hline
\end{tabular}

TABLE-2

PRECISION AND ACCURACY OF GERMANICOL

\begin{tabular}{cccc}
\hline $\begin{array}{c}\text { Nominal } \\
\text { concentration }\end{array}$ & $\begin{array}{c}\text { Germanicol } \\
\text { obtained }(\mathrm{a}, \mathrm{b})\end{array}$ & Precision $(\mathrm{c})$ & Accuracy (d) \\
\hline \multicolumn{4}{c}{ Intra-day batch } \\
\hline 150 & 148.9 & 1.63 & 99.3 \\
300 & 297.8 & 1.49 & 99.6 \\
600 & 599.4 & 1.46 & 99.9 \\
\hline \multicolumn{4}{c}{ Inter-day batch } \\
300 & 148.8 & 1.84 & 99.2 \\
600 & 298.2 & 1.70 & 99.4 \\
\hline
\end{tabular}

${ }^{\mathrm{a}}$ Concentration in $\mathrm{ng}$ band ${ }^{-1}$, ${ }^{\mathrm{b}}$ Mean from six determination $(\mathrm{n}=6)$, 'Precision as coefficient of variation $(\mathrm{CV} \%)=[($ standard deviation $) /$ (concentration found $)] \times 100, \mathrm{~d}$ accuracy $(\%)=[($ concentration found $) /($ nominal concentration $)] \times 100$

\begin{tabular}{lll} 
TABLE-3 & \\
\multicolumn{3}{c}{ ROBUSTNESS OF THE METHOD } \\
\hline \multicolumn{1}{c}{ Optimization condition } & \multicolumn{2}{c}{ Germanicol } \\
\cline { 2 - 3 } & SD & $\%$ RSD \\
\hline Mobile phase from hexane: chloroform $(55: 45$, & 2.47 & 0.022 \\
v/v; 50:40, v/v; 53:47, v/v; 58:42, v/v) & & \\
Mobile phase volume (18, 20 and 22 mL) & 1.79 & 0.011 \\
Duration of saturation $(10,20$ and $30 \mathrm{~min})$ & 2.15 & 0.016 \\
Activation of TLC plate $(2,5$ and $7 \mathrm{~min})$ & 2.34 & 0.019 \\
\hline
\end{tabular}




\begin{tabular}{cccccc}
\hline \multicolumn{7}{c}{ TABLE-4 } \\
RECOVERY STUDIES OF GERMANICOL \\
\hline $\begin{array}{c}\text { Concentration } \\
\text { added to } \\
\text { analyte }(\%)\end{array}$ & $\begin{array}{c}\text { Theoretical } \\
(\mathrm{ng})\end{array}$ & $\begin{array}{c}\text { Added } \\
(\mathrm{ng})\end{array}$ & $\begin{array}{c}\text { Detected } \\
(\mathrm{ng})\end{array}$ & $\begin{array}{c}\text { Recovery } \\
(\%)\end{array}$ & $\begin{array}{c}\text { RSD } \\
(\%)\end{array}$ \\
\hline- & 300 & - & - & - & - \\
50 & - & 450 & 446.8 & 99.3 & 1.32 \\
100 & - & 600 & 597.0 & 99.5 & 1.14 \\
150 & - & 750 & 748.5 & 99.8 & 1.07 \\
\hline
\end{tabular}

2 (F. nitida), sample 4 (F. palmata) and sample 5 (Ficus vasta) were found to contain germanicol (Figs. 4-7) while it was completely absent in sample 3 (F. ingens) (Fig. 8). The content of germanicol in the $F$. carica, F. nitida, F. palmata and $F$. vasta were found to be $0.21 \pm 0.01 \%, 0.22 \pm 0.03 \%, 1.06 \pm$ $0.01 \%, 0.27 \pm 0.01 \%$, w/w, respectively. The authors are privileged to perform this comparative estimation of germanicol for the first time in five above mentioned species of genus Ficus collected from Kingdom of Saudi Arabia by a validated HPTLC method. The findings of this experiment may prove

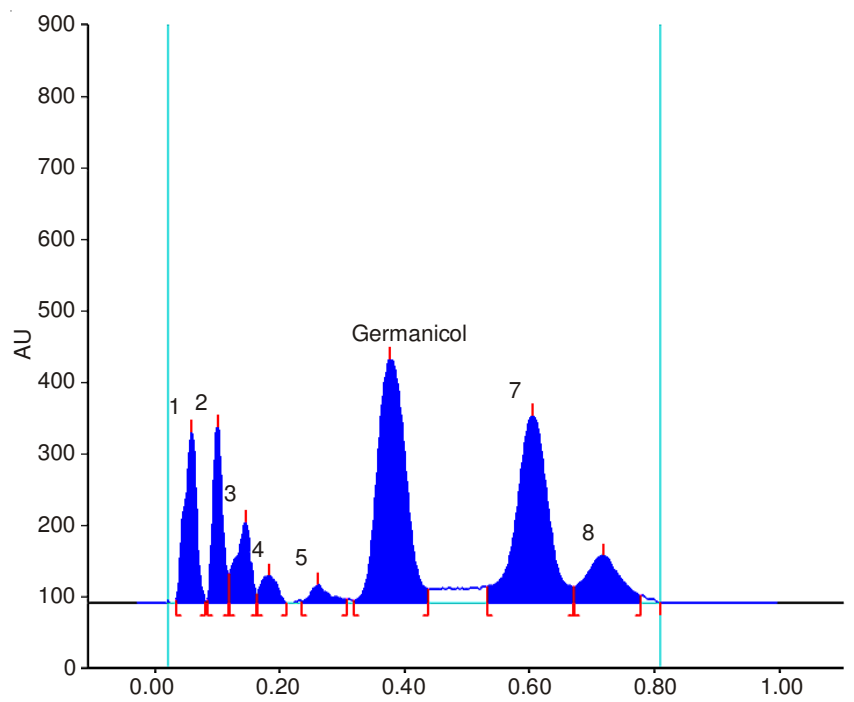

Fig. 4. Chromatogram of sample 1 scanned at $525 \mathrm{~nm}$ (germanicol; $\mathrm{R}_{\mathrm{f}}=$ $0.39)$; mobile phase: hexane: chloroform $(55: 45, \mathrm{v} / \mathrm{v})$

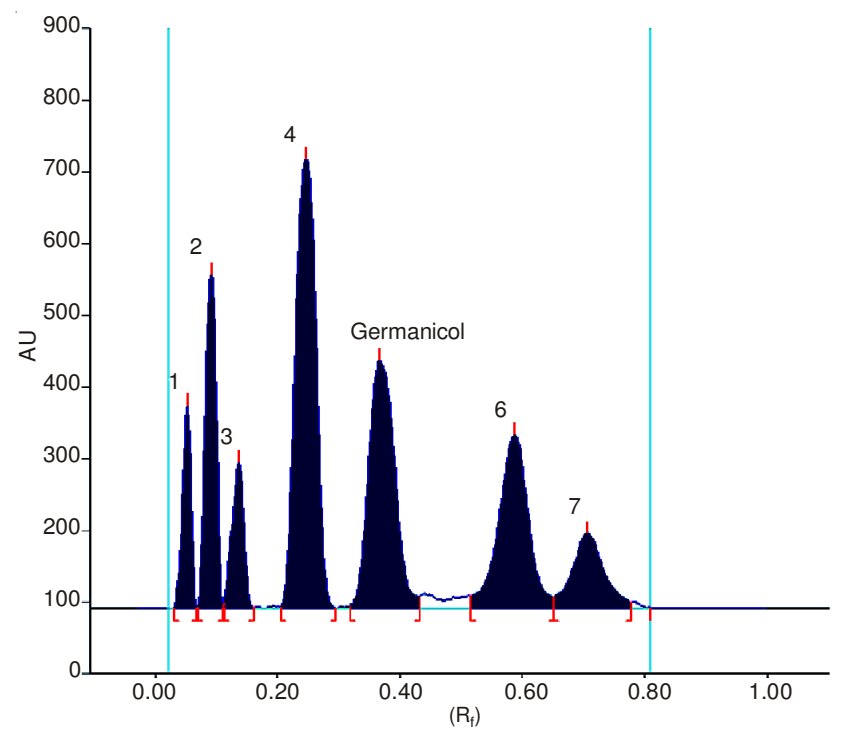

Fig. 5. Chromatogram of sample 2 scanned at $525 \mathrm{~nm}$ (germanicol; $\mathrm{R}_{\mathrm{f}}=$ $0.39)$; mobile phase: hexane: chloroform $(55: 45, \mathrm{v} / \mathrm{v})$

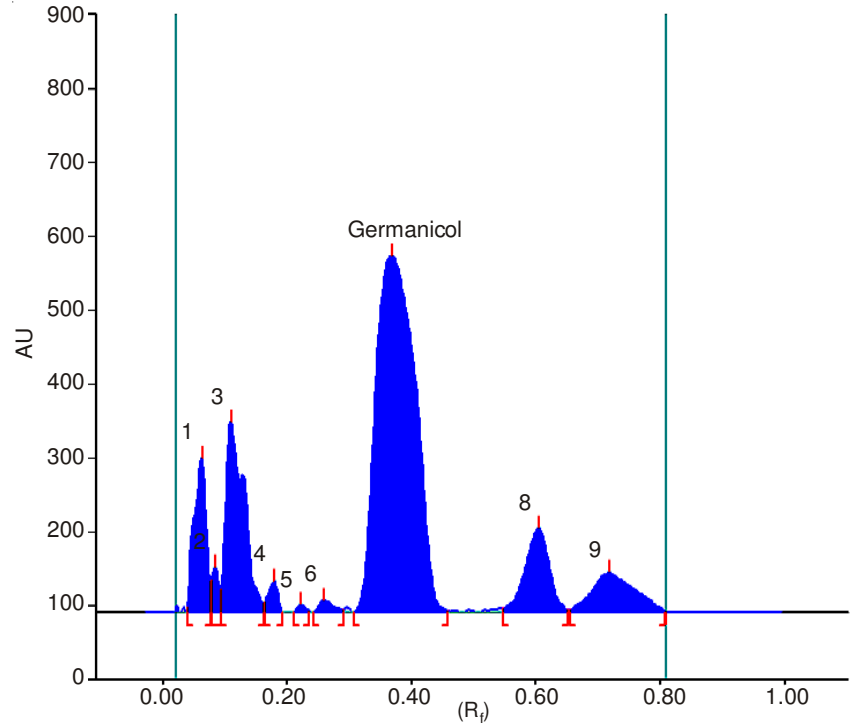

Fig. 6. Chromatogram of sample 4 scanned at $525 \mathrm{~nm}\left(\right.$ Germanicol; $\mathrm{R}_{\mathrm{f}}=$ $0.39)$; mobile phase: hexane: chloroform $(55: 45, \mathrm{v} / \mathrm{v})$

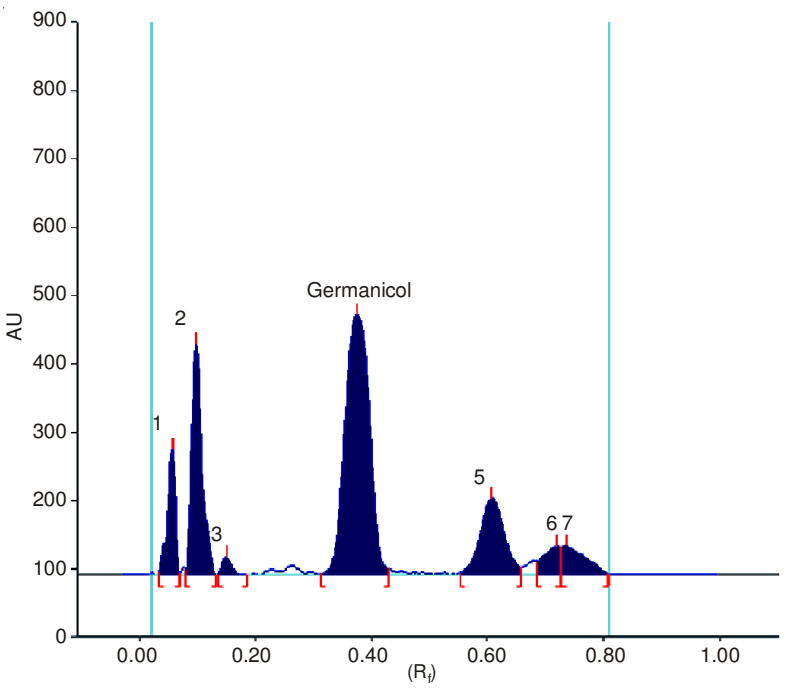

Fig. 7. Chromatogram of sample 5 scanned at $525 \mathrm{~nm}$ (germanicol; $\mathrm{R}_{\mathrm{f}}=$ $0.39)$; mobile phase: hexane: chloroform $(55: 45, \mathrm{v} / \mathrm{v})$

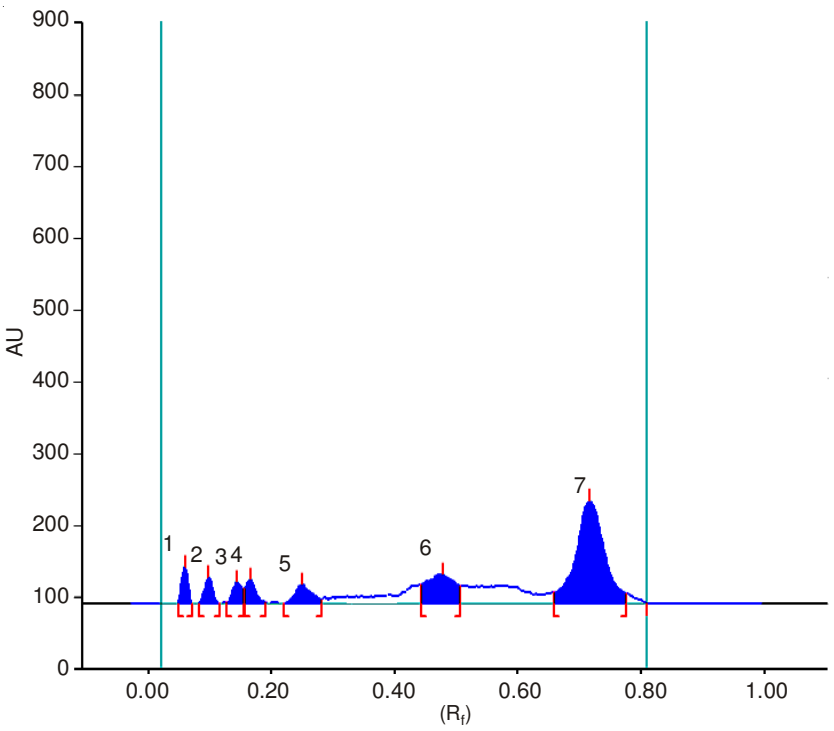

Fig. 8. Chromatogram of sample 3 scanned at $525 \mathrm{~nm}$ (germanicol is absent); mobile phase: hexane: chloroform $(55: 45, \mathrm{v} / \mathrm{v})$ 
the existence of chemotypes present in genus Ficus that may be due to some external or internal factors. The outcomes of this experiment may be utilized to select the species having high content of germanicol ( $F$. palmata and $F$. vasta) for herbal formulations and also to assure the content uniformity in other crude drug materials possessing germanicol.

Triterpenoids are secondary metabolites and plays a vital role in health care system. There are two known major pathways for the biosynthesis of the isoprene unit, one based on mevalonic acid and 1-deoxyxylulose ${ }^{27}$. The formation of secondary metabolites in the plants is greatly affected by extrinsic (e.g., climate, altitude, soil $\mathrm{pH}$ etc.) as well as intrinsic factors (e.g., age, gender, genotype etc.), which are most often beyond our control. To compensate the effect of these external and internal factors on the production of secondary plant metabolites, the developed HPTLC method was found to be an important analytical technique for separation, detection, identification and quantification of germanicol in this experiment.

\section{Conclusion}

In recent years, because of its several benefits like low operation cost, high sample throughput and need for minimum sample clean up, the high performance thin layer chromatography (HPTLC) has become a conventional analytical approach for the quality control of herbal drugs ${ }^{28}$. It is widely used for the identification, assay and the testing for purity, stability, dissolution or content uniformity of raw materials (herbal and animal extracts, fermentation mixtures, drugs and excipients) and formulated products (pharmaceuticals, cosmetics and nutrients $)^{29}$. Cancer is the most dreaded disease in the world as well as in Kingdom of Saudi Arabia and causes large number of deaths every year. It is now a well established fact that the herbal drugs having antiinflammatory potential may play a role to inhibit cancer ${ }^{30}$ and it is also reported that the Ficus species were used traditionally as an anticancer $\operatorname{drug}^{31}$. Since, germanicol has good anti-inflammatory effect ${ }^{24}$, it can also be active against cancer. The detection of germanicol in the extracts of four species of Ficus in this experiment justifies the use of Ficus as anti-cancer drug in folk medicines. Further studies can be designed to explore the mechanism of action, its bioavailability (concentration in blood plasma) and degradation kinetics of germanicol. The above proposed HPTLC method can also be employed for exploration of germanicol in chemotaxonomically related genera of the plant kingdom.

\section{ACKNOWLEDGEMENTS}

The authors acknowledge the continuous support of research center, College of Pharmacy, King Saud University, Riyadh, Kingdom of Saudi Arabia.

\section{REFERENCES}

1. R.D. Harrison, Bioscience, 55, 1053 (2005).

2. J. Hutchinson, J.M. Dalziel and R.W.J. Keay, Flora of West Tropical Africa, Crown Agents, London, edn. 2 (1958).

3. W.L. Wagner, D.R. Herbst and S.H. Sohmer, Manual of the Flowering Plants of Hawaii, Universit of Hawaii and Bishop Museum Press, Honolulu, Vol. 2 (1999).

4. N. Ronsted, G. Salvo and V. Savolainen, Mol. Phylogenet. Evol., 43, 190 (2007).

5. C. Chunyan, S. Bo, L. Ping, L. Jingmei and Y. Ito, J. Liq. Chromatogr. Rel. Technol., 32, 136 (2008).

6. M.S. Chang, Y.C. Yang, Y.C. Kuo, Y.H. Kuo, C. Chang, C.M. Chen and T.H. Lee, J. Nat. Prod., 68, 11 (2005).

7. Y.H. Kuo and Y.C. Li, J. Chin. Chem. Soc., 44, 321 (1997).

8. Y.C. Li and Y.H. Kuo, Chem. Pharm. Bull. (Tokyo), 48, 1862 (2000).

9. Y.H. Kuo and Y.M. Chaiang, Chem. Pharm. Bull. (Tokyo), 47, 498 (1999).

10. O.A. Basudan, M. Ilyas, M. Parveen, H.M.H. Muhisen and R. Kumar, J. Asian Nat. Prod. Res., 7, 81 (2005).

11. E.P. Lansky, H.M. Paavilainen, A.D. Pawlus and R.A. Newman, J. Ethnopharmacol., 119, 195 (2008).

12. E. Noumi and F.L. Fozi, Cameroon Pharm. Biol., 41, 330 (2003).

13. O. Çaliskan and A. Aytekin Polat, Sci. Hortic., 128, 473 (2011).

14. S.C. Mandal, T.K. Maity, J. Das, B.P. Saha and M. Pal, Nat. Prod. Sci., 4, 174 (1998).

15. C.V. Rao, A.R. Verma, M. Vijayakumar and S. Rastogi, J. Ethnopharmacol., 115, 323 (2008).

16. R.K. Singh, S. Mehta, D. Jaiswal, P.K. Rai, G. Watal, J. Ethanopharmacol., 123, 110-114 (2009).

17. V.T. Nguyen, V.H. Nguyen, M.H. Le and T.X. Le, Tap Chi Hoa Hoc., 40, 75 (2002).

18. USFDA National Nutrient Database for Standard Reference, Release 26 (2013).

19. G. Topcua, A. Ertas, U. Kolakb, M. Ozturk and A. Ulubelenb, ARKIVOC, 195 (2007).

20. L.B. Rojas, M. Grignon-Dubois, B. Rezzonico and A. Usubillaga, Nat. Comput., 40, 565 (2004).

21. S. Mishra and S. Sahoo, World J. Pharm. Pharm. Sci., 2, 1781 (2013).

22. C.Y. Ragasa, D.L. Espineli and C.C. Shen, Nat. Prod. Res., 26, 1869 (2012).

23. C.Y. Ragasa, Espineli and Shen, Chem. Pharm. Bull. (Tokyo), 59, 778 (2011).

24. D.K. Kim, J.P. Lim, J.W. Kim, H.W. Park and J.S. Eun, Arch. Pharm. Res., 28, 39 (2005).

25. A.C. Casabuono and Pomilio, Lipids, 32, 205 (1997).

26. International Conference on Harmonization (ICH) of Technical Requirements for Registration of Pharmaceuticals for Human Use, Harmonised Triplicate Guideline on Validation of Analytical Procedures: Methodology, Recommended for Adoption at Step 4 of the ICH process on November by the ICH Steering Committee, IFPMA, Geneva (1996).

27. J.T. James and I.A. Dubery, Molecules, 14, 3922 (2009).

28. M.F. Alajmi, P. Alam and F. Shakeel, J. Planar Chromatogr., 26, 475 (2013).

29. G. Biringanine, M.T. Chiarelli, M. Faes and P. Duez, Talanta, 69, 418 (2006).

30. L. Berkovich, I. Ron, G. Earon, S. Abu-Ghanem, A. Rimmon and S. Lev-Ari, Harefuah, 151, 629 (2012).

31. E.P. Lansky, H.M. Paavilainen, A.D. Pawlus and R.A. Newman, J. Ethnopharmacol., 119, 195 (2008). 